\title{
Rare cause of aortic regurgitation
}

\section{Carina Arantes, Nuno Salomé, Alberto Salgado, Sérgia Rocha}

Department of Cardiology, Hospital de Braga, Braga, Braga, Portugal

\section{Correspondence to} Dr Carina Arantes, arantescarina@gmail.com

Accepted 20 July 2016
CrossMark

To cite: Arantes $C$, Salomé N, Salgado A, et al. BMJ Case Rep Published online: [please include Day Month Year] doi:10.1136/ bcr-2016-216475

\section{DESCRIPTION}

Quadricuspid aortic valve is a rare congenital anomaly with an estimated incidence of $0.008-$ $1.46 \% .{ }^{1}$ It is often detected incidentally at the time of surgery or at autopsy; however, with advances in imaging techniques the diagnosis is easier and also made earlier. ${ }^{2}{ }^{3}$

We report the case of a 40-year-old man who was referred to our department for the evaluation of asymptomatic aortic regurgitation. $\mathrm{He}$ had history of hypertension and dyslipidaemia. On cardiac auscultation, a grade II/VI diastolic murmur was heard on the left sternal border; remainder physical examination was unremarkable. The transthoracic echocardiography showed mild left ventricular enlargement and aortic regurgitation grade III/IV; the aortic valve appeared abnormal with asymmetric cusps and possibly with one accessory cusp (figure 1).

Transesophageal echocardiography revealed a quadricuspid asymmetric aortic valve with two equal larger cusps and two unequal smaller cusps (figure 2). This aspect was confirmed by MRI (figure 3 and video 1) and no other cardiac abnormality was found. Since the patient was asymptomatic, he was kept in regular follow-up to monitor progression of his aortic regurgitation and no specific treatment was indicated.

This case demonstrated that the multimodality imaging approach is a valuable tool in the characterisation of the mechanism of valvular insufficiency and for a proper characterisation of the valve.

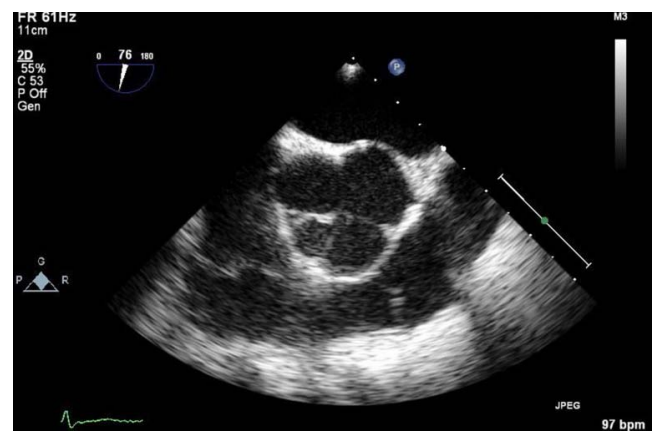

Figure 2 Two-dimensional transesophageal short-axis view of the aortic valve in diastole with the view of $X$-shaped commissural aortic valve pattern.

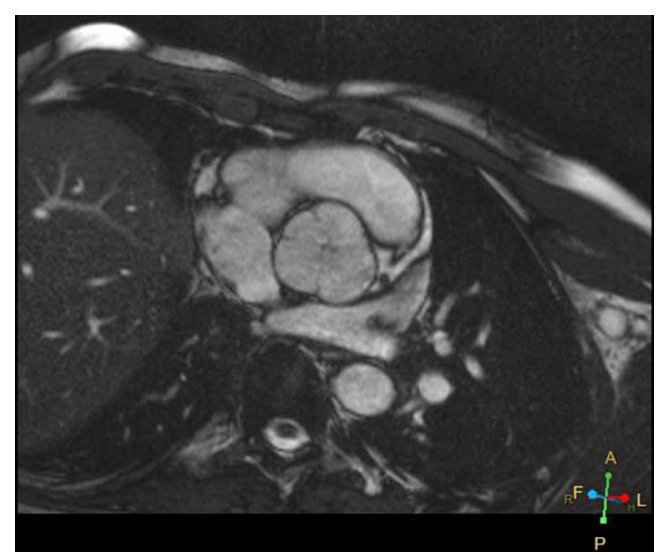

Figure 3 MRI confirmed the presence of an asymmetric aortic valve with four cusps.

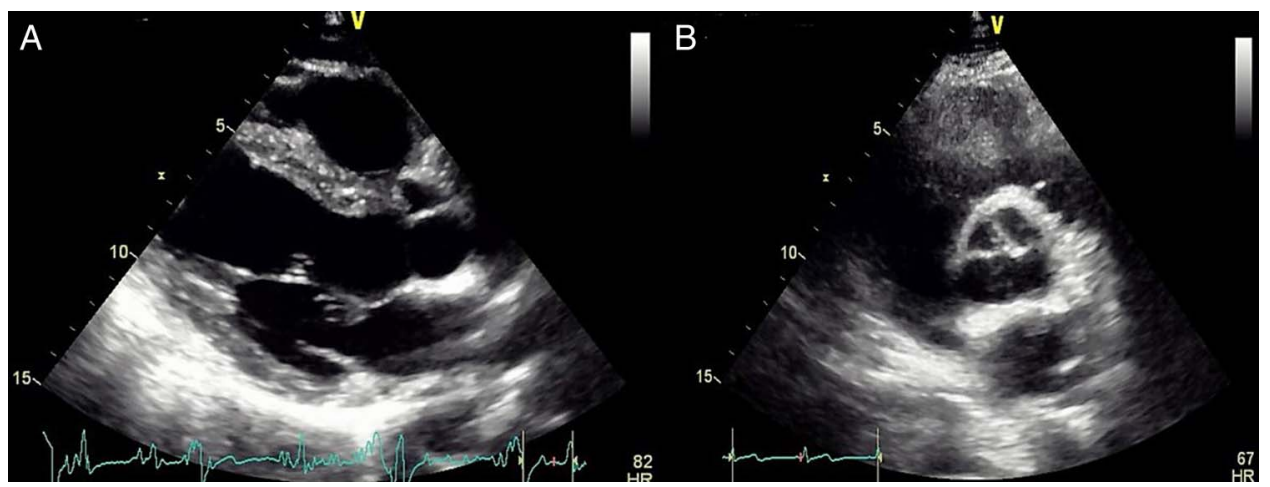

Figure 1 Two-dimensional transthoracic long-axis $(A)$ and short-axis $(B)$ view of the aortic valve. 


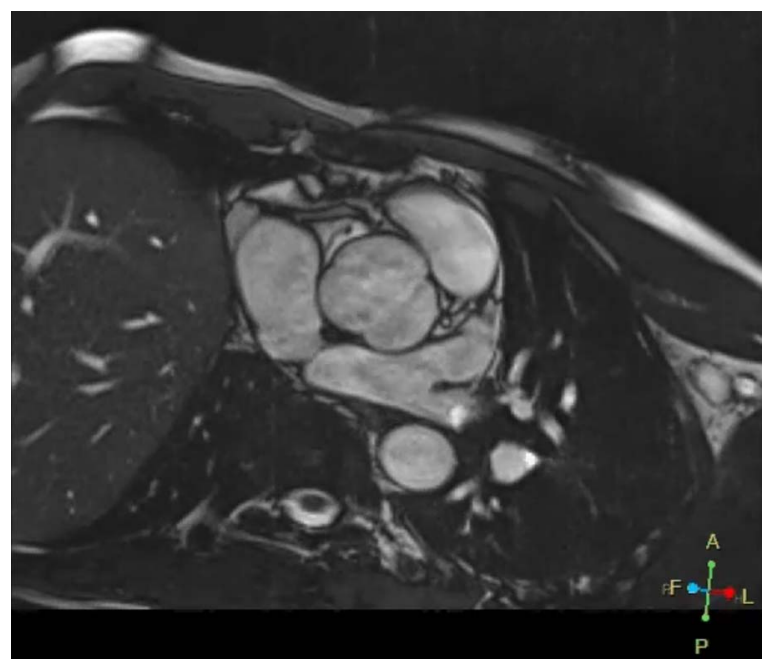

Contributors CA collected the data and wrote the manuscript. All the authors were involved in this clinical case and contributed to the conception of the work, reviewed the manuscript for important intellectual content and gave final approval of this article.

Competing interests None declared.

Patient consent Obtained.

Provenance and peer review Not commissioned; externally peer reviewed.

\section{REFERENCES}

1 Hayakawa M, Asai T, Kinoshita T, et al. Quadricuspid aortic valve: a report on a 10-year case series and literature review. Ann Thorac Cardiovasc Surg 2014;20 (Suppl):941-4.

2 Tsang MY, Abudiab MM, Ammash NM, et al. Quadricuspid aortic valve: characteristics, associated structural cardiovascular abnormalities, and clinical outcomes. Circulation 2016;133:312-19.

3 Jagannath $A D$, Johri $A M$, Liberthson $R$, et al. Quadricuspid aortic valve: a report of 12 cases and a review of the literature. Echocardiography 2011;28:1035-40.

Vídeo $1 \mathrm{MRI}$ confirmed the presence of an asymmetric aortic valve with four cusps.

\section{Learning points}

- Quadricuspid aortic valve is a very rare congenital malformation and it has been associated with other cardiac congenital malformations, such as coronary arteries anomalies. ${ }^{1}$

- Echocardiographic examination plays an important role in the diagnosis with the view of $X$-shaped commissural aortic valve pattern in diastole compared to the ' $Y$ ' morphology in the trileaflet valve. Other imaging techniques may be useful for further characterisation of the valve and to identify other defects. ${ }^{1}$

- This condition usually evolves to aortic regurgitation which manifests in adulthood. The surgical approach is determined by the leaflet morphology and may consist of valvular replacement or repair (tricuspidisation or bicuspidisation). ${ }^{23}$

Copyright 2016 BMJ Publishing Group. All rights reserved. For permission to reuse any of this content visit

http://group.bmj.com/group/rights-licensing/permissions.

BMJ Case Report Fellows may re-use this article for personal use and teaching without any further permission.

Become a Fellow of BMJ Case Reports today and you can:

- Submit as many cases as you like

- Enjoy fast sympathetic peer review and rapid publication of accepted articles

- Access all the published articles

- Re-use any of the published material for personal use and teaching without further permission

For information on Institutional Fellowships contact consortiasales@bmjgroup.com

Visit casereports.bmj.com for more articles like this and to become a Fellow 